\author{
Military Technical College \\ Kobry El-Kobbah, \\ Cairo, Egypt.
}

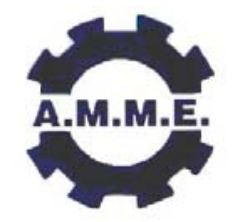
$13^{\text {th }}$ International Conference
on Applied Mechanics and
Mechanical Engineering.

\title{
THE MECHANICAL DESIGN AND CONSTRUCTION OF A TRUCK-MOUNTED SCATTEROMETER PLATFORM
}

\author{
HALIM* A., MAHMOOD* N.N., ALI* A., JAMIL * H. \\ MAHMOOD* K.A., AHMAD* Z., IBRAHIM* N., BREVERN** P.V., CHUAH** H.T., \\ $\mathrm{KOO}^{* *}$ V.C. and SING** L.K.
}

\begin{abstract}
The construction of mobile microwave scatterometer involved the consideration to ensure the platform and equipment selection full-filled technical requirement and safety standard in Malaysia. Designing, and modification works involved engineering calculations and methodology in determining and selecting a suitable hydraulic telescopic boom that suit a selected platform available in the market. The platform is also a delivery system for microwave remote sensing equipment and other accessories to any locations in Malaysia. Total loading to be carried by the platform is about $4500 \mathrm{~kg}$ and its overall weight must be $16,000 \mathrm{~kg}$ as recommended by hydraulic telescopic boom manufacturers. The telescopic boom will elevate $30 \mathrm{~kg}$ microwave scatterometer system and antenna to a maximum height of $27 \mathrm{~m}$, and can also be rotated through $360^{\circ}$. An optical encoder is incorporated in the system to enable tracking or monitoring angular movement of the hydraulic telescopic boom when positioned towards required target. Provision is also provided for future up grading of the system.
\end{abstract}

\section{KEY WORDS}

Mobile Platform, Microwave Scatterometer, Antenna Mounting.

* Malaysian Centre for Remote Sensing, No. 13, Jalan Tun Ismail, 50480 Kuala Lumpur. Tel : 03-26966926 Fax : 03-26973360. e-mail : halim@macres.gov.my.

** Faculty of Engineering and Technology, Multimedia University, Jalan Ayer Keroh L Ama, 75450 Melaka, Malaysia. Tel:+606-252 3004 Fax:+606-231 6552. e-mail : pv.brevern@mmu.edu.my. 


\section{INTRODUCTION}

This is a joint venture project between Malaysian Centre for Remote Sensing (MACRES) and Multimedia University (MMU) The project is an effort by MACRES to strengthen Malaysia's capability in fundamental microwave remote sensing. The task is to design mechanical system including mechanism for antenna mounting. Understanding the material properties of aluminium plates and brackets and tensile properties of mild steel fasteners for bolt and nuts are necessary in designing antenna mounting., to detect antenna inclination angle is also incorporated into the system.

The scope of the work is to design and making mobile platform and equipment selection and finally execute modification work to make it suitable to house work cabin, telescopic boom, microwave remote sensing scatterometer system, diesel generator for the system power requirement. Concealed type diesel power generator is selected for its low noise and low vibration factor. Telescopic boom selected must be able to deliver microwave system to a height determined by the researchers and can be positioned towards required direction by computer signal from the work cabin. Material for boom construction must be of the type that produce minimum deflection and vibration under wind induced forced and under its own weight. Suitable room air-conditioning system to ensure equipment and system long life span and conducive working environment.

\section{MOBILE PLATFORM SELECTED}

$200 \mathrm{hp}$ engine is selected for the mobile platform. The mobile platform will float on its four hydraulic stabilizers for safe operation. This hydraulic stabilizer will also function as vibration dampers.

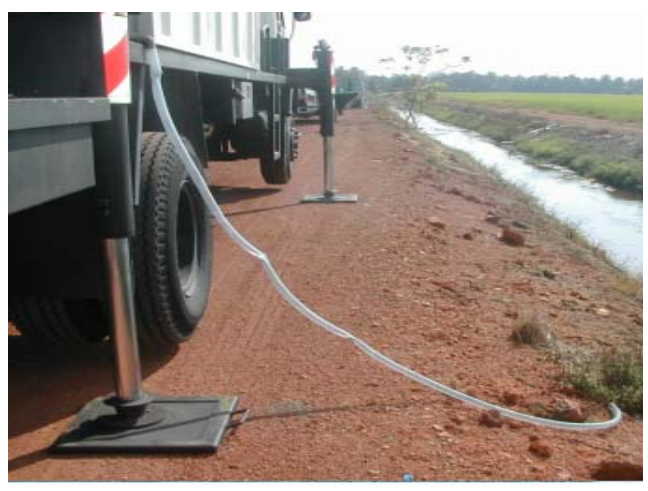

Fig. 1 : Stabilizer as vibration damper.

\section{DEFLECTION OF TELESCOPIC BOOM, Y}

Moment of inertia I, slop, deflection y and other perimeters are required to determine vehicle stability at site [1].

$$
+E l \frac{d^{2} y}{d x^{2}}=M \ldots . . .(1)
$$


Table 1. Deflection of beam members

\begin{tabular}{|c|c|}
\hline Beam & $\begin{array}{c}\text { Total Deflection }(\mathbf{m}) \text { of } \\
\text { Beams }\end{array}$ \\
\hline$A, B, C, D, E$ & $\Sigma y=1338.88 \times 10^{-5}$ \\
\hline
\end{tabular}

\section{Transverse Vibration of Telescopic Boom}

A cantilever experiences transverse deflection or static deflection under its own weight due to gravity [2]. With $\underline{\delta}$ as the deflection, its vibration is derived as,

$\begin{aligned} \text { Frequency } & =\frac{1}{2 \pi} \sqrt{\frac{g}{\delta}} \quad \mathrm{Hz} \ldots \ldots . . .(2) \\ & =4.31 \mathrm{~Hz} \text { (low mechanical vibration) }\end{aligned}$

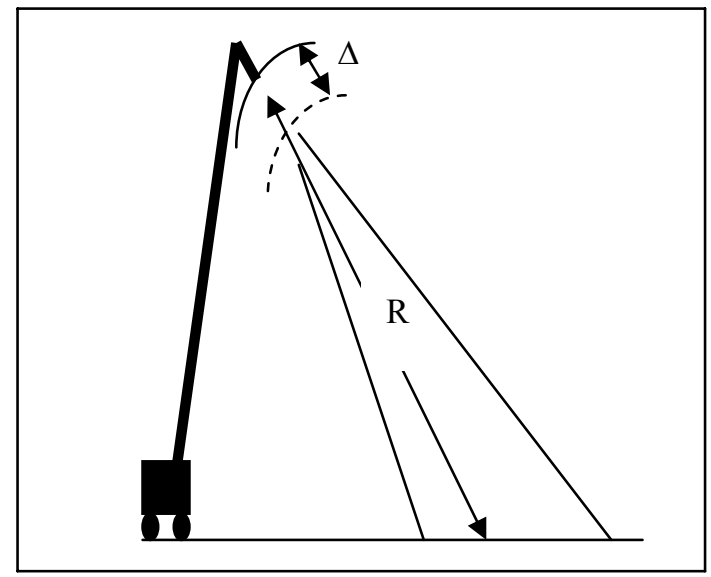

Figure 2. Geometry of scatterometer and target.

Target distance, $R$ of $100 \mathrm{~m}$ with microwave speed equal to that of speed of light which is , $c=3 \times 10^{8} \mathrm{~m} / \mathrm{s}$. Time taken to and fro,

$$
\frac{200 \mathrm{~m}}{c}=\frac{200 \mathrm{~m}}{3 \times 10^{8} \mathrm{~m} / \mathrm{s}}=0.67 \mathrm{~s}
$$

Time taken by microwave to the target and back to the receiver is 0.67 microsecond. The limiting frequency is

$$
\frac{1}{t}=f=\frac{1}{0.67}=1.5 \mathrm{MHz}
$$

Thus, only frequency of more than $1.5 \mathrm{MHz}$ will cause problem to system accuracy.

Vibration at this rate is considered low and the time interval is enough for microwave to hit the target and return to the receiver and recorder for registeration! Anenometer for wind speed measurement is also installed to ensure save working weather condition.(Forbidden at Beufort 6.00) 


\section{POWER REQUIREMENT}

Power requirement of the system is provided by concealed type $12.5 \mathrm{KVA}$ diesel generator. Provision for additional power requirement is provided for near future upgrading of the mobile microwave scatterometer.

\section{Antenna Mounting}

For antenna and microwave component mounting, diameter of bolt and fasteners are taken seriously. Extra factor of safety for bolt sizes were also considered. Taking the moment about $\mathrm{H}_{\mathrm{m}}$, [3], is one of the method used to determine diameter and stresses in mounting fasteners (bolt and nuts).

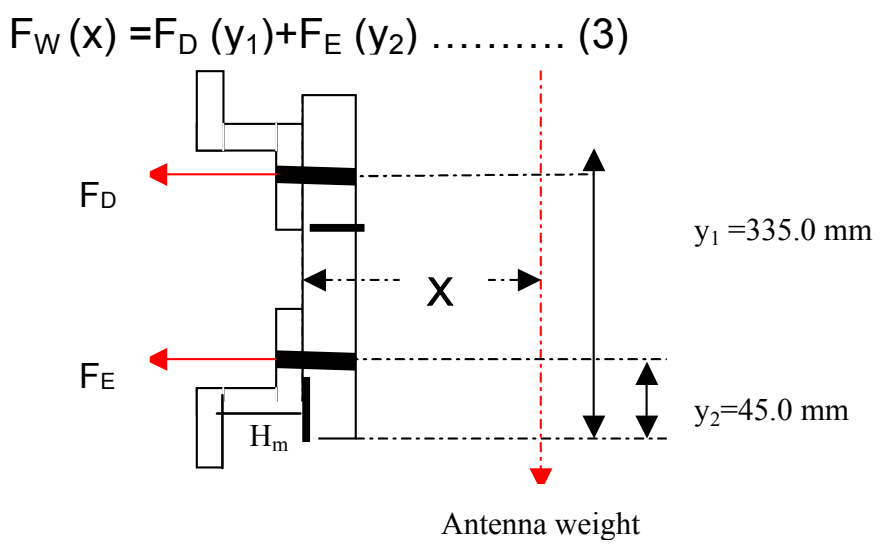

Fig 3: Stresses in fasteners in horizontal antenna mounting

Bolt and nuts of nominal sizes of $6.0 \mathrm{~mm}$ are used to ensure safety, easy handling and to compensate for unexpected factors relating to safety [4].

Mounting is done by taking advantage of the C-beam used as sky platform at the top of telescopic boom.

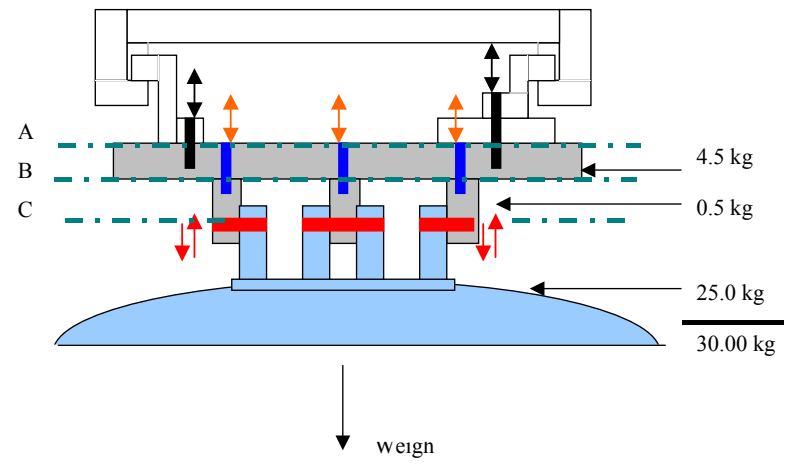

Fig. 4. Mounting bracket and stresses in fasteners

\section{RESULT}

Test measurement and onsite measurements are done by using four polarization modes $(\mathrm{HH}, \mathrm{HV}, \mathrm{VV}, \mathrm{VH})$, at various incidence angle, $\theta$, ranging from $0^{\circ}$ to $60^{\circ}$. 


\section{Calibration test}

This is done on trihedral $31.0 \mathrm{~m} \mathrm{HH}$ at MACRES testing site:
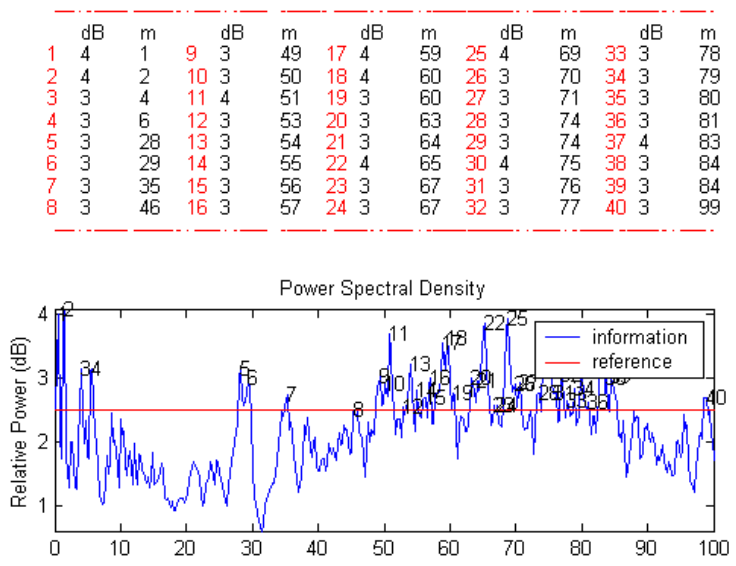

Fig. 5: Point target test

\section{Field Work (Paddy) Test}

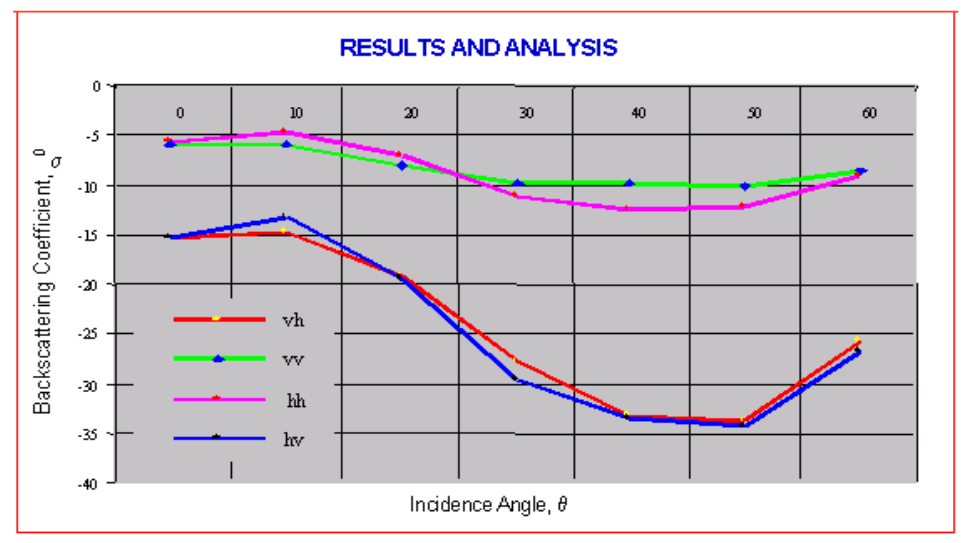

Fig. 6: Backscattering coefficient, $\sigma^{\mathrm{o}}$ vs Incidence angle, $\theta$

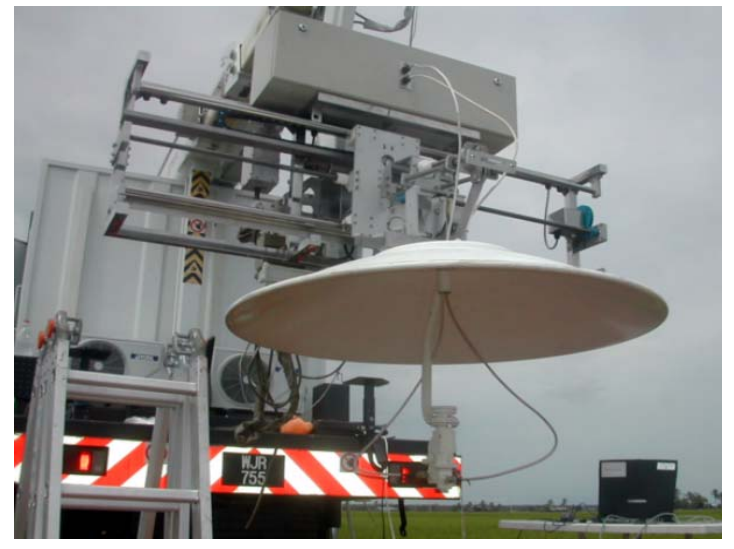

Fig 7: Upgraded to semi-automatic mounting mechanism

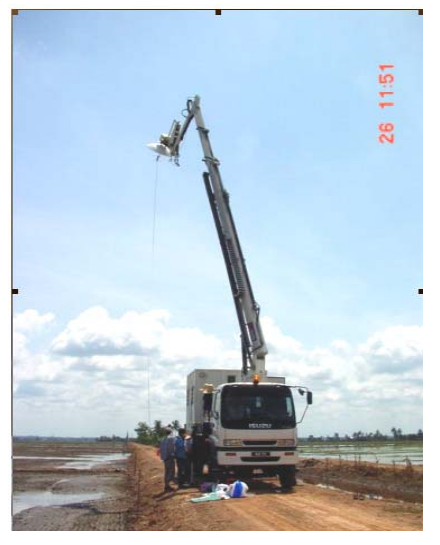

Fig 8: MSS-Mobile Scatterometer System collecting backscattering data in the paddy field. 


\section{CONCLUSION}

Most of the field works are conducted in a state of Selangor. A measurement has been conducted at Sungai Burung paddy field area by using a ground-based mobile C-band scatterometer system. The measurement result showed a typical response of backscattering coefficients as compared to other reports.

Fig 6 , showed the result of the measured backscattering coefficient, $\sigma_{\circ}^{\circ}$, of the paddy at various incidence angle, $\theta$. Each point on the graph represents a mean of 20 independent measurements. This result showed that the backscattering coefficient increases at incidence angle close to nadir and then decreases until certain point and increases again. This trend is similar to the results reported by other research groups [5]. Observation result concluded that the mechanical system comprising of telescopic boom, antenna mounting, diesel power generator, optical encoder for angular tracking all worked perfectly. Satisfactory and acceptable data qualities are achieved. The speed at which microwave transversed the space is too great for mechanical vibration to give any adverse effect to the backscattering measurement.

This preliminary result proved that this system will be one of the useful and most reliable tool for microwave remote sensing research in Malaysia. This system will be used to develop theoretical model for major crops such as paddy, oil palm and rubber. System upgrading and modification will be carried out once the present data collection exercise is completed and data analysis proved the reliability of the mobile platform system. L-band is the next frontier for earthbound mobile microwave remote sensing system in Malaysia. In 2006 antenna mounting has been upgraded to semi-automatic to speed up backscattering data collection.

\section{ACKNOWLEDGEMENT}

The authors and the team wish to thank En. Raja Zainol Abdulllah from AIDP Kuala Selangor, resident of Sungai Burung for their support during the field measurement work.

\section{REFERENCES}

1. Problem and Solutions in Engineering Mechanics- Static and Dynamics. V.SMokashi 1999. Tata McGraw-Hill Publishing Company Limited. Pg. 217/218

2. Mechanics of Machines Advanced Theory and Examples. John Hannah \& R.C Stephens. 1972. Edward Arnold Publishing, London. Pg. 345.

3. Mechanics of Engineering Materials. P.P Benham, R.J Crawford.1994. ELBS with Longman Group U.K Limited. Pg. 599

4. Mechanical Machine Design, R.C. Bahl, V.K. Goel. $1^{\text {st }}$. Edition 1974. Standard Publishers Distributors. Pg. 369.

5. Soo Bum Kim, Byung Wook Kim, Young Kyun Kong, and Young-Soo Kim, 2000. Radar Backscattering Measurement of Rice Crop Using X-band Scatterometer, IEEE Trans. Geosci. Remote Sensing, Vol 38, pp 1467-1471. 